\title{
EXPOSIÇÃO À MORTE E BIOPOLÍTICA: UMA ABORDAGEM A PARTIR DO RACISMO DE ESTADO E DO PARADIGMA IMUNITÁRIO
}

\section{EXPOSURE TO DEATH AND BIOPOLITICS: AN APPROACH FROM THE RACISM OF STATE AND THE PARADIGM OF IMMUNIZATION}

\author{
Angela Couto Machado Fonseca \\ Universidade Federal do Paraná - UFPR - (Curitiba, PR, Brasil) \\ Dhyego Câmara de Araújo \\ Universidade Federal do Paraná - UFPR - (Curitiba, PR, Brasil)
}

Recebimento: 26 out. 2017

Aceitação: 18 dez. 2017

\begin{abstract}
Como citar este artigo / How to cite this article (informe a data atual de acesso / inform the current date of access):
FONSECA, Angela Couto Machado; ARAÚJO, Dhyego Câmara de. Exposição à morte e biopolítica: uma abordagem a partir do racismo de Estado e do paradigma imunitário. Revista da Faculdade de Direito UFPR, Curitiba, PR, Brasil, v. 63, n. 1, p. 117-140, abr. 2018. ISSN 2236-7284. Disponível em: <http://revistas.ufpr.br/direito/article/view/55306>. Acesso em: 30 abr. 2018. DOI: http://dx.doi.org/10.5380/rfdufpr.v63i1.55306.
\end{abstract}

\section{RESUMO}

A discussão aqui proposta pretende analisar a produção da morte e a exposição à morte por meio das lentes fornecidas pela biopolítica e não sob o viés jurídico-político tradicional. Busca-se, pelo uso de metodologia analítica, problematizar que uma devida tematização da morte requer o deslocamento nos modos de se pensar vida/morte como fenômenos meramente jurídicos para pensá-los como efeitos de relações de poder pertencentes a uma lógica da modernidade política. A partir da noção de Racismo de Estado de Michel Foucault e do Paradigma Imunitário de Roberto Esposito, a produção da morte é colocada dentro do problema de como a biopolítica se converte em tanatopolítica. Ambos os autores permitem conceber na biopolítica moderna um circuito entre proteção e negação da vida, que se desdobra por uma cisão valorativa entre tipos de vida acobertados pela proteção e outras enviadas para a produção da morte. O que se busca com essa análise é a ampliação do debate sobre a relação vida e morte no cenário político contemporâneo, pela proposição de um desvio das análises pautadas apenas no critério da (i)legalidade de promover a morte. A intenção é a de questionar como, dentro dos próprios moldes de funcionamento de uma moderna política da vida, a produção da morte é chamada a participar. Trata-se de perceber como a semântica da biopolítica permite acessar um funcionamento de proteção da vida e produção da morte operante, à revelia da tonalidade humanista e do valor da vida humana assumida pelos modernos discursos jurídicos e políticos. A atenção a essa lógica de poder atuante na modernidade e seus mecanismos de funcionamento que produzem ordenação hierarquizada da vida e exposição à morte é o que se busca, minimamente, com esta análise.

\section{PALAVRAS-CHAVE}

Biopolítica. Exposição à morte. Racismo de Estado. Paradigma imunitário. 


\begin{abstract}
The discussion here proposed aims to analyse the production of death and exposure to death through the lens provided by biopolitics and not under the traditional legal-political bias. It is sought, through analytical methodology, to problematize that an efficient thematization of death requires the displacement in the ways of thinking life/death as purely juridical phenomena to think of them as effects of relations of power belonging to the political modernity logic. From Michel Foucault's notion of State Racism and Roberto Esposito's Immune Paradigm, the production of death is placed within the problem of how biopolitics becomes into tanatopolitics. Both authors allow us to conceive in modern biopolitics a circuit between protection and denial of life, which is unfolded by an evaluative split between types of life covered by protection and others sent for the production of death. What is sought with this analysis is the expansion of the debate about the relation of life and death in the contemporary political scenario, by proposing a deviation from the analyses based only on the criterion of the legality or illegality of promoting death. The intention is to question how, within the very working patterns of a modern politics of life, the production of death is called to participate. It is a question of perceiving how the semantics of biopolitics allows the access to a functioning life-protection and production of death that is operant, in the absence of humanistic tonality and the value of human life assumed by modern legal and political discourses. The attention to this logic of power active in the modernity and its functioning mechanisms that produces hierarchical ordering of life and exposure to death is what is sought, minimally, with this analysis.
\end{abstract}

\title{
KEYWORDS
}

Biopolitics. Exposure to death. State racism. Paradigm of immunization.

\section{INTRODUÇÃO}

As discussões no campo do direito acerca das condições da morte ocorrem, em grande medida, pelo viés da legitimidade e aplicação da pena capital. Em geral, as teorizações a esse respeito giram em torno da elaboração de uma justificativa que apresente como plausível e justa a determinação da pena de morte por meio de uma sentença. Ou, do contrário, a sua vedação, pautada em argumentos sensíveis à promoção e valorização dos direitos humanos, de acordo com um paradigma universal de justiça e equidade que tenha na dignidade da pessoa humana o seu pilar de sustentação. Figura, nesse contexto, a dignidade humana como elemento que deve ser capaz de manter todo o arcabouço jurídico-político contra as investidas efetivadas sobre a vida dos cidadãos. Trata-se, em suma, seja para justificá-la, seja para rechaçá-la, de formulações teóricas preocupadas com a noção de legitimidade da pena de morte e daquele que teria o direito de determiná-la: o poder soberano.

Uma das bases que sustentam essa perspectiva de valorização da vida e, consequentemente, de negação da pena de morte, deriva da concepção moderna de homem como sujeito de direito abstrato, dotado de liberdade, autonomia e dignidade. Grosso modo, tais narrativas constroem-se em torno da concessão ao sujeito da necessária proteção de sua vida, haja vista esta ter se tornado um 
bem inalienável e indisponível, sobretudo depois dos regimes totalitários dos séculos XIX e XX, cujo ápice é, em grande medida, localizado nas atrocidades cometidas pelo nazismo e pelo fascismo no século passado.

Em que pese a pertinência dos debates específicos sobre o valor da vida e da pessoa humana, que alimentam a análise jurídica de não legitimação do poder soberano para matar por meio de uma sentença penal condenatória, entendemos que existem outras perspectivas de análise sobre as condições da morte para além da sua (i)legitimidade na figura pontual da pena de morte.

A proposta de pensar a ocorrência da morte fora do plano restrito de sua legitimidade soberana - registro que trata da possibilidade ou não da condenação e o cometimento de assassinatos - se justifica pela percepção de que na realidade social ocorrem continuados eventos nos quais a vida é exterminada ou exposta à morte, sem que tais eventos possam na sua totalidade ou de modo fácil encaixar-se naqueles parâmetros da legitimidade.

Se por um lado é viável balizar a produção da morte questionando se ela cabe ou não ao Estado e, diante dos casos concretos de sua ocorrência, fazer pesar sua condição de ilicitude, por outro lado escapa, a esse modelo interpretativo, o alcance compreensivo de que certos modos de existência são mais vulneráveis à morte. Mais que isso, tal vulnerabilidade, ligada ao risco e à concretização da morte, não se explica pelos parâmetros de morte pensados no ordenamento jurídico. Para enunciar tais vidas expostas à morte, basta aqui, de modo breve, atentarmos para a condição de maior precariedade (BUTLER, 2015) da população negra, LGBTI, de mulheres, das pessoas em situação de rua, das prostitutas, daqueles que vivem em favelas, etc. Sugerimos, assim, que o evento da morte, para ser devidamente pensado, requer a agregação de outros referenciais analíticos.

O terreno teórico-filosófico que nas últimas décadas - mais precisamente, desde meados da década de 1970 - tem se ocupado de pensar as relações entre vida/morte e poder é aquele que Michel Foucault veio a denominar por biopolítica.

Não se trata, a partir dessa perspectiva, de sustentar a legitimidade ou não do poder soberano para matar em determinados casos, tampouco de reivindicar a vida como lugar privilegiado de proteção a partir do qual se irradiariam todos os demais direitos próprios da qualidade do humano. Trata-se, por seu turno, de explicitar as técnicas e as práticas que fizeram da vida biológica o alvo privilegiado do poder na política ocidental, bem como seus inúmeros desdobramentos no campo social.

Essa tomada da vida pelo poder, como pensada pela biopolítica, problematiza que o objeto das relações de poder não é o sujeito de direitos, mas sim a população como coleção de processos biológicos - o que implica a perda de sentido do apelo à igualdade dos cidadãos e sua dignidade 
derivada de atributos subjetivos. O horizonte biopolítico trata da gestão da vida, o que admite pensar que essa administração organize em diferentes níveis as vidas e possa privilegiar ou barrar características biológicas elaboradas como benéficas ou prejudiciais.

Por tal viés de análise, permite-se vislumbrar a construção, em torno do que se entende por vida, de uma teia capaz de capturá-la naquilo que se considera como da ordem do orgânico e natural, possibilitando o surgimento de saberes estatísticos a respeito de taxas de natalidade, mortalidade e morbidade, a implementação de programas de previdência e políticas públicas de saúde, a organização do espaço urbano para melhor circulação de pessoas, mercadorias e doenças, etc. É com a biopolítica que se opera um importante deslocamento de ênfase no qual a vida torna-se objeto de gestão calculada. Aquela “[...] morte, que se fundamentava no direito do soberano se defender ou pedir que o defendessem, vai aparecer como o simples reverso do direito do corpo social de garantir sua própria vida, mantê-la ou desenvolvê-la” (FOUCAULT, 2011a, p. 148-149).

Com a identificação do surgimento da biopolítica no século XVIII feita por Michel Foucault, as relações entre poder e vida, bem como entre poder e morte, ganharam novos matizes. Não mais um poder soberano de "fazer morrer e deixar viver", mas a partir de então um poder que se manifesta de modo diverso e sob uma nova alcunha: denominado biopoder, caracteriza-se pelo "fazer viver e deixar morrer” (FOUCAULT, 2010). Ora, se de acordo com o diagnóstico foucaultiano há a partir do século XVIII um predomínio de um tipo de poder que se dirige à promoção da vida, como explicar as diversas situações em que não se verifica o seu estímulo e proliferação, mas, exatamente o contrário, a sua exposição à morte ou mesmo o seu extermínio?

Tal qual sugerida por Foucault, essa nova tecnologia do poder, que se dirige à vida naquilo que possui de orgânico e biológico, opera segundo comandos de sua promoção, incitação e acúmulo, mas também, de sua constante normalização e controle - o que pode, paradoxalmente, ocasionar seu extermínio. Isto é, a vida é efetivamente estimulada e fabricada de forma contínua, todavia esse esforço constante no entorno de sua gestão produz diferentes tipos de vida com diferentes níveis de valor. Algumas vidas tornam-se, nessa complexa relação entre poder e bíos, passíveis de morte.

O ponto que tanto Foucault quanto Esposito perceberam, mesmo que tenham desenvolvimentos diversos e, por vezes, Esposito conteste e critique Foucault, é o de que a biopolítica revela um circuito de proteção e risco no que se refere à vida. Para proceder a uma real e séria discussão dos processos de incitação e proteção da vida, é preciso colher o caráter biopolítico dos mecanismos que realizam tais processos, assim como perceber que pertence aos seus próprios movimentos, na defesa da vida, também a produção da morte. Para produzir e gerir vidas defensáveis, também são produzidas vidas descartáveis. Esse é um reverso circular do funcionamento das políticas 
sobre a vida.

Se é assim, no particular e no cenário brasileiro, podemos pensar, num primeiro momento a partir do recorte de gênero, a situação vivida pela comunidade LGBTI. Tais vidas, posicionadas como menos válidas pelo padrão heternormativo vigente, são cotidianamente abaladas por violências continuadas e produção de mortes. Ainda que se possa argumentar que tais mortes são efeitos indesejados de uma sociedade injusta, é preciso também se lembrar do cenário aqui delineado, em que práticas de poder voltadas para a vida desenham os corpos e os desenham também em seu valor e utilidade. Resulta de uma hierárquica disposição das vidas e suas condições de validade no cenário político a visibilização “desviada” e "anormal” dos corpos LGBTI. A vida dos LGBTI, construída como “abjeta”, permite investidas negativas sobre ela - é permissão para exposição à morte.

De acordo com o banco de dados do Grupo Gay da Bahia (GGB), atualizado diariamente no site "Quem a homotransfobia matou hoje”, 318 LGBTI foram assassinados no Brasil em 2015. São índices que revelam um crime de ódio a cada 27 horas, dos quais 52\% das vítimas são gays, 37\% travestis, $16 \%$ lésbicas e $10 \%$ bissexuais $^{1}$.

Ainda, conforme a pesquisa intitulada “Trans Murder Monitoring”, da ONG Trangender Europe $^{2}$, o Brasil lidera o ranking mundial de países que mais assassinam a população trans. A Associação Nacional de Travestis e Transexuais (Antra) aponta que 90\% da população travesti e transexual é forçada a entrar na prostituição, em razão do preconceito sofrido em locais de trabalho formalizados e por conta da evasão escolar. A prostituição e a rua contribuem fortemente para a submissão à violência e a morte. A permissão, e mesmo a circulação do entendimento de que essa posição e esse lugar sejam os que cabem a tais formas de vida, são práticas que reiteram a exposição à morte. São vidas deixadas para morrer ou sofrer violência.

Também o recorte econômico e de raça diz muito sobre as vidas que, do modo como são reguladas e ordenadas pelas práticas de poder, recebem a sua gradação valorativa. Os dados sobre ocorrência de violência em favelas e sobre a população negra não são menos alarmantes.

Uma sentença divulgada pela Corte Interamericana de Direitos Humanos (Corte IDH), instituição judicial autônoma da Organização dos Estados Americanos (OEA), determinou que o governo brasileiro terá o prazo de um ano (até o dia 11 de maio de 2018) para reabrir as investigações sobre duas chacinas ocorridas em 1994 e 1995 na comunidade Nova Brasília, no Complexo do Alemão, durante operações policiais no Rio de Janeiro. Em cada chacina foram mortos 13 jovens ${ }^{3}$.

\footnotetext{
${ }^{1}$ Tais dados foram acessados em 16 set. 2017 no seguinte endereço eletrônico: <https://goo.gl/Hq5qZO>.

${ }^{2}$ Informação disponível em: <https://goo.gl/FkLPJq>.

${ }^{3}$ Disponível em: <https://goo.gl/DPAqJP>. Acesso em: 16 set. 2017.
} 
Para além dessas duas chacinas, é sintomática a higienização diuturna que procede nas favelas. As características raciais em muito têm demarcado as vidas selecionadas para viver ou morrer. O Atlas da Violência tem cor, lugar e idade. Morrem mais jovens negros favelados e periféricos do que jovens brancos. Entre 2005 e 2015, verificamos dois cenários completamente distintos. Se em relação a indivíduos não negros verificamos uma diminuição de $12,2 \%$ na taxa de mortalidade, no que se refere a indivíduos negros houve um crescimento de 18,2\% na taxa de homicídios ${ }^{4}$.

Levando em consideração a hierarquização social promovida pelo biopoder, Foucault vislumbra a existência de um paradoxo no quadro desenhado pela tecnologia biopolítica, ou seja, a contradição levada a cabo por um tipo de poder cuja promoção da vida é o seu objetivo, mas que resulta na produção da morte. Tal situação apresenta a transmutação da biopolítica em tanatopolítica, quer dizer, remete a essa conversão do fazer viver em fazer morrer.

Se na década de 70 foi possível a Foucault identificar o formato paradoxal dessa relação entre poder e vida/morte, os seus trabalhos posteriores não enfrentaram exaustivamente a problemática levantada pela dicotomia biopolítica/tanatopolítica. Para o filósofo, a emergência do biopoder trouxe consigo, para o interior do Estado, a figura do racismo ${ }^{5}$, a qual permite, nesse domínio da vida, instaurar um corte capaz de determinar quem deve viver e quem deve morrer (FOUCAULT, 2010, p. 214).

No arcabouço filosófico foucaultiano, o desdobramento da biopolítica em tanatopolítica ${ }^{6}$ foi pensado em termos de um paradoxo. Sua reflexão nos é necessária para localizar a biopolítica e com ela as relações de pertinência de um poder que, ao ter como objeto o fazer viver, também exercita o fazer morrer. Continua-se o debate com Roberto Esposito, precisamente porque seu pensamento quer

\footnotetext{
${ }^{4}$ INSTITUTO DE PESQUISA ECONÔMICA APLICADA (IPEA) / FÓRUM BRASILEIRO DE SEGURANÇA PÚBLICA (FBSP). Mapa da Violência 2017. P. 33. Disponível em: <https://goo.gl/hVBdaf>. Acesso em: 16 set. 2017. ${ }^{5}$ Não se trata o racismo como uma figura nova ou inventada nas tramas da biopolítica. Em sua genealogia do racismo, Foucault demonstra o seu surgimento como um discurso histórico-político de enfrentamento em relação a um discurso jurídico-filosófico - proeminente desde a Idade Média - que buscava deslegitimá-lo reivindicando a luta das raças como seu mote de embate - raças vistas como dois grupos distintos marcados pela origem local, língua ou religião. Posteriormente, a história da luta das raças tornou-se, de um lado, a luta de classes, e de outro, o racismo, nesse momento lido a partir de uma matriz biológica e que será tomado pelo biopoder para servir de justificativa e operacionalização do seu exercício de morte. Para uma análise detalhada sobre esse movimento genealógico da figura do racismo biológico de Estado, consultar a Aula de 28 de janeiro de 1976 do curso Em defesa da Sociedade (FOUCAULT, 2010).

${ }^{6}$ Ao falarmos de tanatopolítica, o que aparece é a conversão da biopolítica - do fazer viver - no seu contrário: fazer morrer. Tanto Michel Foucault, quanto Roberto Esposito (autores aqui trabalhados), perceberam que a própria biopolítica opera como tanatopolítica, ela mesma se converte no seu contrário em suas práticas de regulação da vida. Embora esses autores tenham pensado essa conversão em diferentes bases - Foucault como um paradoxo e Esposito pelo paradigma imunitário -, ambos a diagnosticam e a percebem como um problema inescapável. Assim, vida e morte no cenário político contemporâneo são pensadas por esses dois autores a partir do viés da biopolítica. É a biopolítica que permite compreender as práticas de poder que atuam sobre a vida, seja no seu incremento ou na sua invalidação e morte.
} 
apontar para uma possível resposta ao paradoxo, concedendo lugar privilegiado para os desdobramentos tanatopolíticos nos exercícios de poder contemporâneos. Esposito provoca seu leitor a considerar que os eventos políticos atuais somente podem ser devidamente compreendidos quando usamos o quadro categorial da biopolítica e com ele as condições de vida e morte.

A esse respeito, podemos retornar às páginas que abrem a introdução do livro Bios: Biopolítica e Filosofia, do filósofo italiano, onde são mencionadas várias situações ocorridas em diferentes lugares do mundo - como por exemplo a Guerra ‘humanitária’ no Afeganistão em 2001; o resgate de reféns presos pelo comando checheno em Moscou em 2002, que matou tanto civis quanto terroristas; e o relatório da ONU em 2004, informando que em Ruanda cerca de 10.000 crianças resultaram de violações étnicas ocorridas mediante um estupro coletivo no confronto dos Hutus com os Tutsis - para expor que o fio invisível que amarra e permite ler eventos tão distintos e distantes é o fio da biopolítica. Em suas palavras: “No seu centro está a noção de biopolítica. Só a partir dela é que acontecimentos que escapam de uma interpretação mais tradicional, como aqueles que acabamos de evocar, encontram um sentido de conjunto que vá além da sua simples manifestação” (ESPOSITO, 2010, p. 22).

A identificação de um tipo de poder que, muito embora não parta do Estado em direção à vida/morte dos sujeitos, mas que o atravessa, reconfigurando-o dentro de um quadro distinto da análise restrita da (i)legalidade sobre a produção da morte, revela a pertinência da análise que ora se propõe.

\section{MICHEL FOUCAULT E RACISMO DE ESTADO: A “PENA DE MORTE” BIOPOLÍTICA}

A complexidade do tema da produção da morte, lida a partir do prisma da biopolítica, tornase, nesse sentido, mais complexa e aguda, na medida em que busca lançar luz às artimanhas de um tipo de poder - o biopoder - que investe sobre o fato da vida, a despeito, inclusive, da proibição jurídica sobre a morte (seja como pena de morte, seja como ato ilícito). O tema da biopolítica emerge na economia do pensamento foucaultiano em 1976, ano em que é lançado A vontade de saber (FOUCAULT, 2011a), primeiro volume de sua história da sexualidade, bem como no curso por ele ministrado no Collège de France entre 1975-1976, intitulado Em defesa da Sociedade (2010), em que o autor melhor desenvolve os desdobramentos de tal noção ao introduzir a discussão acerca do racismo de Estado. Nas palavras do autor:

Aparece - nesse momento - o que é um paradoxo em comparação aos próprios fins e à forma primeira desse discurso [da biopolítica] - um racismo de Estado: um racismo que uma 
sociedade vai exercer sobre ela mesma, sobre os seus próprios elementos, sobre os seus próprios produtos; um racismo interno, o da purificação permanente, que será uma das dimensões fundamentais da normalização social (FOUCAULT, 2010, p. 52-53).

Assim, o conceito de biopolítica surge em sua genealogia dos micropoderes disciplinares ${ }^{7}$ identificado como uma das facetas do biopoder, esse tipo de poder que tem suas raízes cravadas no século XVIII e que tem na vida seu ponto de acumulação e investimento, mas também gestão e controle. A proliferação da vida, nesses termos, dá-se concomitantemente à sua regulação, cuja marca normalizadora poderá ser acompanhada de práticas vinculadas a um esquema de purificação social e biológica pelo discurso do racismo de Estado.

Se, ao analisar as disciplinas, Foucault parece passar ao largo do poder soberano, quando se depara com as operações dadas no entorno da população ele o retoma, não para tratá-lo nos mesmos termos das teorias tradicionais da filosofia política, e sim para percorrê-lo na esteira de seu movimento genealógico em relação às práticas de normalização. Isto é, o poder soberano passa a ter uma posição de pertinência no seu pensamento, ao se verificarem os processos de regulação e controle das populações que se dão no e pelo Estado. Contudo, a atenção do autor volta-se à complexa rede de saber-poder engendrada no tecido social, a qual possibilitou, inclusive, o surgimento da população, enquanto objeto e instrumento de atuação (FOUCAULT, 2010, 2011a), momento no qual se verifica também a emergência do racismo de Estado, como tecnologia de normalização do corpo-espécie.

Levando-se em consideração os textos mencionados, a compreensão do conceito de biopolítica passa, necessariamente, pela distinção feita pelo autor a respeito de dois modos básicos de poder que ocorreram na história do ocidente, não sem certa continuidade, denominados por ele de poder soberano, o primeiro, e de biopoder, o segundo. Uma possível distinção entre essas duas formas de exercício de poder pode dar-se, conforme diz Foucault, a partir das rupturas dos modos de se conceber o fenômeno da morte. De acordo com o próprio autor:

\begin{abstract}
Pode-se dizer que o velho direito de causar a morte ou deixar viver foi substituído por um poder de causar a vida ou devolver à morte. Talvez seja assim que se explique esta desqualificação da morte, marcada pelo desuso dos rituais que a acompanhavam. A preocupação que se tem em esquivar a morte está menos ligado a uma nova angústia que, por acaso, a torne insuportável para as nossas sociedades, do que o fato de os procedimentos do poder não cansarem de se afastar dela. Com a passagem de um mundo para o outro, a morte era a substituição de uma soberania terrestre para uma outra, singularmente mais poderosa; o fausto que a acompanhava era da ordem do cerimonial político. Agora é sobre a vida e ao longo de todo o seu desenrolar que o poder estabelece seus pontos de fixação; a morte é o limite, o momento que lhe escapa; ela se torna o ponto mais secreto da existência, o mais “privado” (FOUCAULT, 2011a, p. 151, grifos do autor).
\end{abstract}

\footnotetext{
${ }^{7}$ Nesse sentido a biopolítica é, como o poder disciplinar, uma das tecnologias do biopoder, mas, diferente do poder disciplinar, não atua sobre corpos individuais, mas sobre a vida biológica de massas e populações.
} 
Enquanto o poder soberano caracterizava-se por atuar no confisco e apreensão do trabalho e dos bens, assim como, no seu limite, da própria vida, o biopoder engloba a tal forma e atuação outras peças cujas funções se darão a partir de outros comandos. Deixa-se de operar tão somente pela via da exclusão para inscrever-se no real por meio de técnicas de incitação e reforço, de controle e vigilância e, por fim, de organização e regulação das forças que lhe são submetidas. Trata-se, segundo Foucault, “[...] de um poder destinado a produzir forças, a fazê-las crescer e a ordená-las mais do que a barrálas, dobrá-las ou destruí-las. Com isso, o direito de morte tenderá a se deslocar ou, pelo menos, a se apoiar nas exigências de um poder que gere a vida e a se ordenar em função de seus reclamos” (FOUCAULT, 2011a, p. 148).

Um dos privilégios do qual gozou o poder soberano por muito tempo se referia ao direito de vida e morte em relação a seus súditos. Sua derivação formal pode ser encontrada na figura da patria potestas do direito romano, mediante a qual se concedia ao pai de família o poder de dispor da vida de seus filhos e de seus escravos. Tal não é a concepção, todavia, dos teóricos clássicos a respeito da soberania, cuja versão se apresenta nesses moldes, mas de forma atenuada. A relação de poder existente entre soberano e súdito não se dá de maneira que o primeiro o exerça de forma absoluta e incondicionada, senão como uma possibilidade de atuação nos casos em que o soberano se veja ameaçado, seja em sua própria existência, seja na existência de seu território (FOUCAULT, 2011a, p. 147).

O direito de fazer morrer, isto é, da imposição de uma pena de morte, nesses casos, poderia ser percebido no interior daquilo que ao soberano era concedido, ainda que de forma limitada. Seja em seu modelo antigo e discricionário, ou em sua forma moderna limitada, o direito de vida e morte é, como diz Foucault, um direito assimétrico. “O soberano só exerce, no caso, seu direito sobre a vida, exercendo seu direito de matar ou contendo-o; só marca seu poder sobre a vida pela morte que tem condições de exigir. O direito que é formulado como 'de vida e morte’ é, de fato, o direito de causar a morte ou de deixar viver” (FOUCAULT, 2011a, p. 148, grifos do autor). Esse é o paradoxo teórico constitutivo do poder soberano.

No cenário perpassado pela soberania, tanto a vida como a morte não se apresentavam como fenômenos naturais, dotados de certa originalidade ou radicalidade, estando desde sempre entrelaçados pelo poder político, ou, como diz Foucault, “[...] o súdito não é, de pleno direito, nem vivo nem morto” (FOUCAULT, 2010, p. 202). Com efeito, o súdito conformava-se como um ser neutro perante a vida e a morte, isto é, “a vida e a morte dos súditos só se tornam direitos pelo efeito da vontade soberana” (FOUCAULT, 2010, p. 202). Nesse sentido, o poder que permite ao súdito viver só se efetiva no momento mesmo em que se decide a respeito de sua morte. 
Esse desequilíbrio prático, que fazia da vida apenas um efeito da atuação da vontade soberana sobre a morte, dá lugar a um novo tipo de poder-saber emergente, a partir das modificações ocorridas no discurso político do século XIX, que consistiu não na substituição, mas na complementaridade desse direito de soberania. Assim, na esteira da emergência do biopoder não se verifica o desaparecimento da soberania, mas movimentos de interpenetração, de comunicação e de modificação, que, se não a eliminou, transformou-a no seu inverso: o direito de "fazer viver ou deixar morrer” (FOUCAULT, 2010, p. 202).

Essa reorganização das relações entre poder e vida/morte implica a reestruturação do olhar sobre a morte considerado no interior de um sistema legal. Todavia, o que aqui se busca é lançar luz para os desdobramentos e rearticulações envolvidos nesse direito de fazer viver, próprio do ambiente biopolítico, que encobrem não apenas as manifestações de um deixar morrer, como também as de um fazer morrer. A produção da morte em um regime de privilégio da vida apenas pode dar-se, segundo Foucault, acionando o discurso do racismo de Estado, próprio das incursões biopolíticas do século XIX. Segundo o filósofo francês:

O racismo se forma nesse ponto (racismo em sua forma moderna, estatal, biologizante): toda
uma política do povoamento, da família, do casamento, da educação, da hierarquização
social, da propriedade, e uma longa série de intervenções permanentes ao nível do corpo, das
condutas, da saúde, da vida quotidiana, receberam então cor e justificação em função da
preocupação mítica de proteger a pureza do sangue e fazer triunfar a raça (FOUCAULT,
2011a, p. 163).

O pensamento foucaultiano a respeito das relações de poder - e não acerca do poder revelará uma leitura outra sobre o clássico poder soberano, podendo este carregar o biopoder veiculando disciplina, bem como ser agente de práticas biopolíticas (FONSECA, 2002, 2004). O deslocamento realizado pelo biopoder no que se refere a seu modo de concepção e investimento sobre a vida - e a morte - se fez verificar a partir de uma série de técnicas direcionadas aos corpos dos indivíduos - anátomo-política disciplinar do corpo $^{8}$ - e à população tomada enquanto corpo espécie - regulação biopolítica da população.

No curso Segurança, Território, População, Foucault explicita essa relação entre população e soberano nos seguintes termos:

[...] A população é um dado que depende de toda uma série de variáveis que fazem que ela não possa ser transparente à ação do soberano, ou ainda, que a relação entre a população e o soberano não possa ser simplesmente da ordem da obediência ou da revolta. [...] O limite da

\footnotetext{
${ }^{8}$ Em razão dos objetivos do presente trabalho, não serão desenvolvidos os meandros e as peculiaridades do poder disciplinar emergente no século XVII, tão bem detalhado e descrito por Michel Foucault. Para um exame mais profundo da análise, verificar Vigiar e Punir (FOUCAULT, 2011b).
} 
lei, enquanto só se considerar a relação soberano-súdito, é a desobediência do súdito, é o "não" oposto pelo súdito ao soberano. Mas, quando se trata da relação entre o governo e a população, o limite do que é decidido pelo soberano ou pelo governo não é necessariamente a recusa das pessoas às quais ele se dirige (FOUCAULT, 2008, p. 93, grifo do autor).

Sendo assim, Estado soberano e população, no quadro desenhado pela biopolítica, relacionam-se menos em termos de obediência dos súditos em função da vontade soberana do que mediante a implementação de modos de governo nos quais a “condução das condutas” dos sujeitos se dá de acordo com critérios normalizadores (FOUCAULT, 2008, p. 93). Nesse cenário, o governo das populações, na direção do prolongamento de suas vidas, refere-se, do mesmo modo, à construção de populações normalizadas segundo mecanismos de regulação e controle.

O fenômeno da vida/morte, quando lido pelas lentes biopolíticas, pode ser desvelado pelos mecanismos de segurança que giram em torno das taxas de natalidade/mortalidade. A proibição da pena de morte, nesse cenário, parece filiar-se aos desígnios de um poder que busca a majoração e proliferação da vida, ao se resguardar da atuação soberana a vida dos súditos.

Entretanto, o cultivo da vida biológica é sempre pautado por técnicas discursivas e não discursivas que a tomam como objeto privilegiado. Paradoxalmente, esses mesmos critérios são utilizados para apontar as subjetividades do corpo social que, caso não sejam reguladas, normalizadas e, em última instância, exterminadas, colocam em risco a própria viabilidade do corpo políticobiológico da sociedade. Nesse sentido, o governo da população se dá a partir da instauração de uma verdade, a qual, para Foucault, poderá estabelecer divisões raciais hierárquicas e possibilitará, assim, maior exposição à morte de algumas raças em nome da saúde do próprio corpo social.

Nesse sentido, é possível perceber que o racismo segue duas funcionalidades. A primeira promove um corte nisso que se denominou por domínio da vida. Ao ser tomada como corpo-espécie, a população emerge como um conglomerado orgânico em que se verifica o aparecimento das raças em sua qualificação biológica. Assim, o corte operado pelo racismo será capaz de promover o “aparecimento das raças, a distinção das raças, a hierarquia das raças, a qualificação de certas raças como boas e de outras, ao contrário, como inferiores” (FOUCAULT, 2010, p. 214). Com efeito, a demonstração dessa hierarquia das raças permite vislumbrar a distribuição diferencial das subjetividades alocadas no campo da normalidade e da anormalidade e, consequentemente, nas vidas cuja salvaguarda e vulneração se justificam.

A segunda funcionalidade do racismo, que é decorrente dessa primeira, explicita-se por uma relação positiva. Tal relação é sintetizada por Foucault a partir dos seguintes postulados: “quanto mais você matar, mais você fará morrer”; ou “quanto mais você deixar morrer, mais, por isso mesmo, você viverá” (FOUCAULT, 2010, p. 215). No limite, tais considerações arregimentarão um modo de 
atuação do biopoder em que “A morte do outro não é simplesmente a minha vida, na medida em que seria minha segurança pessoal; a morte do outro, a morte da raça ruim, da raça inferior (ou do degenerado, ou do anormal), é o que vai deixar a vida em geral mais sadia; mais sadia e mais pura” (FOUCAULT, 2010, p. 215).

Ao estabelecer o corte - primeira função do racismo -, a tecnologia biopolítica forja subjetividades de acordo com a dicotomia normal/anormal, conferindo ao último toda uma rede de constrições normalizadoras, dada a sua posição hierárquica inferior na escala construída segundo o critério racista. Todavia, o racismo permite ao aparato biopolítico atuar de acordo com uma segunda função, aquela que Foucault chamou de “positiva”. É esta última que realiza a conversão do fazer viver no fazer morrer, quando a própria existência daquelas subjetividades anormais é considerada nefasta à viabilidade e prolongamento do corpo-espécie. Em tais casos vidas são condenadas, são abertas para a morte, em nome da vida da sociedade.

Com efeito, a emergência do biopoder trouxe consigo para o interior do Estado a figura do racismo, a qual permite nesse domínio da vida instaurar um corte capaz de determinar quem deve viver e quem deve morrer (FOUCAULT, 2010, p. 214). Em uma sociedade normalizadora, o poder de matar deve passar necessariamente pelo racismo de Estado ${ }^{9}$. Esta é a condição para que o biopoder, regulamentador da vida, possa exercer o seu oposto. Mesmo porque se assim o faz, ou seja, se atua no domínio da morte, isto apenas pode dar-se em nome da conservação e, sobretudo, do fortalecimento da própria raça ou espécie. Em nome da vida biológica, portanto (FOUCAULT, 2010, p. 216).

Nesse sentido, é a intersecção entre a estatização do biológico e o racismo de Estado que permite, no domínio do biopoder, o exercício do poder soberano de matar. Assim, tirar a vida não significa simplesmente a determinação da morte ou o assassínio direto, mas também modos de matar indiretamente, isto é, a exposição à morte, a multiplicação de riscos de morte para alguns grupos de indivíduos, a morte política, a expulsão, a rejeição, etc. (FOUCAULT, 2010, p. 216) ${ }^{10}$. Desse modo, há que se atentar para todas as vezes em que se aciona o discurso do racismo biológico, porque é nele

\footnotetext{
${ }^{9}$ Sobre isso, cf. nota de rodapé ${ }^{\circ} 5$.

${ }^{10}$ É a partir dessa compreensão da exposição à morte, aberta para vidas que valem menos e por isso são submetidas a circunstâncias de riscos, que temos um exemplo do problema da biopolítica em seu pendor tanatopolítico. Não se trata de morte consentida pelo Estado de modo explícito. O Estado não é o lugar e nem o motor da biopolítica. Ele é atravessado pela lógica biopolítica que o ultrapassa, podendo ser um vetor de atuação biopolítica. Por isso, na presente discussão, há que se cuidar para não confundir pena de morte com a tanatopolítica, pois não se trata de morte justificada legalmente pelo Estado. Mas, diferente disso, de mortes que resultam de relações de poder, estas sim, autorizadas e mesmo postas em funcionamento pelo Estado. Não se trata de mortes legítimas como punição, mas efeitos de formas de regulação dos viventes.
} 
que está contido o exercício da eliminação, direta ou indiretamente, daqueles vistos como perigo para o corpo-espécie.

Nesse contexto, são pertinentes as considerações do autor a respeito do nazismo. Se este representa o desenvolvimento até o paroxismo dos mecanismos de poder que haviam sido introduzidos desde o século XVIII, configurando-se, no seu limite, um Estado racista, assassino e, também, suicida, o acionamento do racismo de Estado pelas estratégias biopolíticas de normalização não é prerrogativa exclusiva de governos totalitários. Como demonstra Foucault, apesar de se constituírem no bojo da configuração do Estado capitalista ou do Estado industrial, também o socialismo não pôde deixar de reativar e reinvestir esses mecanismos biopolíticos e seu correlato, porém não necessário, racista, na mecânica de seu funcionamento de regulação ideal da população (FOUCAULT, 2010, p. 220).

No espaço regulamentado e organizado pelo biopoder, é o racismo a condição para o exercício da morte. Com efeito, se a normalização biopolítica implica o estabelecimento de curvas de normalidade ótimas para as quais deve ser constrangida a população, o movimento de resistência a tais influxos suscita o aparecimento do racismo de Estado como indicação da morte daqueles que representam um risco biológico para a própria espécie. Tais indicações aparecem sob a justificação biológica de degeneração da espécie, de propagação de doenças, de problemas relacionados à hereditariedade, como também relativos à própria força da vida. Todavia, dizem também sobre questões de ordem moral e política, colonizadas, entretanto, pela biologia e que ganham, assim, o estatuto de um rigor científico que possibilita o estabelecimento da vida que merece prosperar e daquelas cujas mortes são necessárias para o prolongamento da espécie.

Vê-se que no cenário da biopolítica - e do racismo de Estado -, a despeito da proibição jurídica da pena capital, a produção da morte em suas variadas formas pode atravessar, inclusive, práticas do campo estatal.

Isso indica que pensar a produção da morte, dentro do terreno da soberania, apenas considerando o discurso legal da pena de morte, mostra-se insuficiente para abarcar os mecanismos de poder que articulam práticas de extermínio da vida. São as mortes daqueles cujas vidas encerramse em um espaço constituído como pernicioso para o corpo-espécie populacional, as mortes não contabilizadas pelo Estado, as mortes praticadas pelo próprio Estado, não por uma autorização judicial, mas como efeitos de poder que se colocam sobre a vida. O que aparece são os corpos expostos ao risco da morte em razão da cor de sua pele, de seus comportamentos, de suas práticas sexuais, de seus modos de vida, de suas posições econômicas, dos locais onde habitam e circulam, que, no limite, dizem mais sobre os espaços que não foram capazes de ocupar: o espaço da 
normalidade biopolítica.

Entretanto, ainda que Foucault evidencie a emergência do racismo de Estado enquanto um contínuo da estatização do biológico que explique a produção de morte para subjetividades fabricadas no terreno da anormalidade, o filósofo francês, conforme afirma o próprio Esposito (2010, p. 23), "nunca conseguiu dar uma resposta exaustiva a essa interrogação - ou, melhor, que sempre hesitou entre diversas respostas, tributárias, por sua vez, de diferentes modos de colocar a questão que levantara”. Diante de interpretações, ou excessivamente negativas, ou radicalmente celebratórias, da biopolítica no cenário contemporâneo, o filósofo italiano busca pensar o paradoxo da biopolítica/tanatopolítica considerando-o como da ordem do enigma, cuja face visível é a da imunização. São as contribuições de Esposito para a discussão aqui proposta que se buscará explorar na sequência.

\section{ESPOSITO E O PARADIGMA IMUNITÁRIO: A PROTEÇÃO NEGATIVA DA VIDA}

Sobre a fenda aberta por Michel Foucault, outras são as reflexões apresentadas por Roberto Esposito a respeito do “enigma da biopolítica”. Em sua obra é elaborado um verdadeiro percurso de desconstrução acerca da capacidade analítica das categorias políticas modernas ${ }^{11}$ em seu alcance compreensivo dos eventos políticos contemporâneos. Sua obra fornece um quadro crítico que acusa a permanência de uma semântica política - dos direitos, do contrato, da liberdade e da democracia incapaz de responder à realidade mais presente.

Mas esse movimento desconstrutivo, de desmontagem conceitual, que procura visibilizar a inefetividade do léxico político moderno, está associado a um movimento de redirecionamento. O sentido interno da denúncia está associado à intenção de propor novos conceitos, que emergem de sua leitura da biopolítica. É na direção, ou melhor, na nova direção assumidamente biopolítica, que seus dispositivos conceituais como comunidade, imunidade e impessoalidade se localizam e pretendem contribuir para o alcance dos acontecimentos políticos.

Suas análises partem de Foucault e polemizam com Foucault, uma vez que o italiano, ao pretender elaborar as condições de uma biopolítica afirmativa, enfrenta o circuito proteção da vida e risco de vida inerente à biopolítica. Esposito pretende superar essa relação em sua face de paradoxo, elaborando o paradigma imunitário, elemento que, em sua leitura, foi a “chave interpretativa” (ESPOSITO, 2010, p. 73) que faltou a Foucault.

\footnotetext{
${ }^{11}$ Categorias políticas como liberdade, democracia, direitos individuais e direitos coletivos, por exemplo.
} 
O enigma segundo o qual a biopolítica, esse conjunto consistente de ações e práticas voltadas para a produção e proteção da vida, reverte-se ou decai numa tanatopolítica, resolve-se, para este autor, pela fórmula da imunização. O acesso à biopolítica pela noção de imunização é fundamental, pois pensa a própria política moderna como imunitária e a biopolítica como sua expressão.

A proposição conceitual precisa da imunidade é apresentada como "proteção negativa da vida” (ESPOSITO, 2010, p. 21), mas não há como alcançar o significado dessa proteção negativa sem relacionar imunidade e comunidade. Numa retomada etimológica não usual, Esposito expõe que comunidade (communitas) deriva de cum e munus. O primeiro termo remete a uma relação - a um 'com' - que é a um só tempo irresistível e impossível, ao passo que o munus - que recebe maior atenção e importância - indica por um lado tarefa, obrigação, ofício, e, por outro, dom. Trata-se de um dom que exige, “o dom que se dá, não o que recebe” (CAMPBELL, 2017, p. 18).

A partir dessa localização etimológica, a comunidade é dissociada da noção de propriedade ${ }^{12}$. A comunidade não é o que integra os sujeitos a partir da apropriação de um próprio que lhes seja dado por natureza. Nem mesmo seria possível pensar em sujeitos, já que não há sequer contrato inaugurado na base da apropriação de elementos inerentes do homem e que os redefina como sujeitos. O desenho do homem da communitas que aparece é de um homem impróprio e ligado pela pura exterioridade do munus - do dever e do dom de dar (ESPOSITO, 2006).

A comunidade, baseada no munus, configura-se como exposição e abertura; apresenta, nesse fazer e não receber, a contínua situação de risco e de perigo extremo de morte ao homem. É dentro desse quadro que a imunidade se coloca. Ela aparece como forma de remediar os excessos de exposição do dom e se desenha como emblema da filosofia política moderna.

Em Termos da Política, Esposito (2017, p. 154) diz que a "salvaguarda da vida humana diante dos perigos da extinção violenta que a ameaçam” explicita a condição biopolítica da modernidade, de modo que "poderia chegar-se a dizer que não foi a modernidade a colocar o problema da autoconservação da vida, mas esta última a pôr em existência, por assim dizer, a 'inventar’ a modernidade como um complexo de categorias em condições de resolver tal problema” (ESPOSITO, 2017, p. 154). Essas passagens são profundamente eloquentes para relacionar a comunidade como a exposição que pode chegar a ser letal (problema biopolítico) e a imunidade como o desdobramento imanente da comunidade para barrar esse seu efeito danoso. Nesse ponto, ignorando todos os importantes desdobramentos da política moderna como imunitária, a definição do paradigma

\footnotetext{
${ }^{12}$ A esse respeito: "il munus che la communitas condivide non è una proprietà o un’appartenenza. Non è un avere, ma, al contrario, un debito, un pegno, un dono-da-dare [...] il commune non è caraterizzato dal proprio, ma dall’improprio” (ESPOSITO, 2006, p. XIII-XIV).
} 
imunitário como proteção negativa encontra a possibilidade de sua compreensão.

Tal como na fisiologia ${ }^{13}$ do corpo humano, o funcionamento da imunização se caracteriza pela proteção da comunidade a partir de sua articulação com elementos negativos, mas que, a partir de tal operação, implicam a criação de uma rede de proteção. Protege na medida em que evita os excessos do dom comunitário, mas é negativa porque nega a comunidade - revela a passagem do comum ao individual. Diante da possibilidade iminente de intensificação daqueles elementos danosos tal rede protetiva é ativada, evitando, assim, fatores de risco produzidos pela própria comunidade. Esses fatores de risco seriam sua desagregação generalizada, a dessubjetivação de seus membros e, no limite, sua morte (ESPOSITO, 2002, 2010; NALI, 2012, 2013): “o sistema imunitário é assim um complexo estratégico de proteção da vida, de seu equilíbrio a partir do desequilíbrio incitado, extremamente dinâmico e homeostático” (NALI, 2013, p. 92).

Conforme exposto por Nali (2013, p. 86), com a demonstração e descrição, pela ciência, do funcionamento do sistema imunológico dos organismos, implantou-se no âmbito da ação política tais ideias, com vistas a produzir mecanismos imunitários e de proteção à comunidade. Junto à descoberta e isolamento dos agentes etiológicos e, em especial, de como se valer de culturas enfraquecidas de tais agentes para induzir um processo de imunização do corpo, transplantaram-se tais saberes para a comunidade. Pressupõe-se que há um mal a afligi-la, requisitando, portanto, meios de reproduzir “de forma controlada o mal do qual deve proteger” (ESPOSITO, 2009, p. 17).

O paradigma imunitário, segundo Esposito, seria representante do único modo interpretativo capaz de restaurar o elo existente entre a biopolítica e a modernidade, uma vez que entende que “só a modernidade faz da autopreservação individual o pressuposto de todas as outras categorias políticas, da soberania à liberdade” (ESPOSITO, 2010, p. 21).

Nesse cenário, a leitura que ora se propõe a partir da imunização aponta que se encare o paradoxal sentido da sedimentação de uma comunidade ligado aos processos de imunização efetivados enquanto resultado da perigosa exposição da vida dessa mesma comunidade. Isto é, o paradigma imunitário como “proteção negativa da vida” (ESPOSITO, 2010, p. 21). A immunitas não

\footnotetext{
${ }^{13}$ É interessante notar que Esposito, ao identificar essa interação discursiva entre os saberes políticos e biomédicos e, empreendendo numa análise etimológica dos termos communitas e immunitas, prontamente identifica que não se trata de um discurso biológico que afeta o campo da política e da defesa da comunidade, mas, antes, de uma construção discursiva no campo da biologia que procura explicar o funcionamento de um organismo a partir de metáforas bélicas e de defesa. O que se consolida em uma leitura analítica corrente na biologia, a imunologia, para, em seguida retornar ao campo das defesas políticas de uma comunidade, de um território, de uma sociedade, de um Estado. Tal retorno, entretanto, marcado neste momento, não apenas por constituir-se como um discurso de guerra e de defesa bélica, mas com ares científicos e epistemológicos.
} 
se refere a uma leitura de poder que o considere como uma força externa atuando sobre a vida a partir do fora (ESPOSITO, 2002), mas que propõe, por outro lado, que “o próprio modo de atuação da vida é conflitual e, portanto, não pode ocorrer à revelia das relações de poder. A imunidade é inteiramente colocada como as formas de proteção da vida em sua inerente relação com o poder” (FONSECA, 2016, p. 70).

Desse modo, vida e morte passam não mais a integrar aquela aparente relação de oposição mútua. Dissolvem-se as fronteiras estanques entre tais termos, bem como entre subjetivação e dessubjetivação, substituindo-se a oposição anterior por uma relação de imanência e inclusão, em que a morte não é mais pensada como o limite externo situado no polo contrário à vida, mas como fenômeno vital (NALI, 2013, p. 90).

A compreensão da biopolítica a partir do paradigma imunitário nos leva a considerá-la como uma exposição controlada da comunidade aos riscos e fatores que a negam e a ameaçam. Nesse sentido, tanto a vida como a subjetividade devem sofrer os infortúnios e vicissitudes de sua própria negação, ainda que de maneira calculadamente controlada, de modo que resulte num fortalecimento da comunidade contra futuras ameaças antagônicas mais fortes, provenientes, contudo, de seu próprio seio. O sistema imunitário, destarte, é tomado pelo filósofo, em estreita correlação com a comunidade, uma vez que a compreende como o próprio motor da imunização (ESPOSITO, 2010).

Essa tradução imediata da vida em política, tal qual sugerida pelo filósofo, ou ainda, essa formulação da política caracterizada como intrinsecamente biológica (ESPOSITO, 2010, p. 21), faz com que não mais se percebam tais relações como uma biopolítica sobre a vida, mas como uma política da vida. A imunização, portanto, sugere uma concepção de imanência entre política e vida, porém, no limite, a imunização necessária à conservação da comunidade pode vir a superar os limites de sua proteção e sobrevivência e se perverter em uma espécie de doença autoimune, como o que se pôde verificar nas atrocidades cometidas pelo nazismo (ESPOSITO, 2010, p. 26).

Segundo Esposito, na experiência nazista, a instrumentalização da morte não vinha apenas como efeito de uma proteção negativa da vida, mas o próprio condicionamento e potenciamento da vida se dava sob uma crescente dialética destinada à produção estendida de morte (ESPOSITO, 2010, p. 24).

Em sua leitura, o regime nazista levou às últimas consequências a biologização da política, ponto que outrora jamais fora alcançado, uma vez que considerou o povo alemão como uma totalidade orgânica, um corpo doente necessitado de uma cura radical e cuja recomendação era a extração e expurgação de seus agentes etiológicos, que consistia, ao fim e ao cabo, "na ablação violenta da parte espiritualmente já morta” (ESPOSITO, 2010, p. 25), bastando lembrar, como prova disso, das ordens 
finais de autodestruição proferidas por Hitler contra todo o povo alemão.

No capítulo dedicado à tanatopolítica (o ciclo do ghenos) em Bios: Biopolítica E Filosofia, assim como no capítulo O Nazismo e Nós, em Termos da Política: comunidade, imunidade, biopolítica, Esposito verticaliza a leitura das ligações próprias e não impróprias ou paradoxais da política da vida como igualmente política da morte. Deixa claro outra distinção sua em relação a Foucault. Se para Foucault é somente com o nazismo e o racismo de Estado que aparece a circularidade entre fazer viver e fazer morrer, entre soberania e biopolítica, para o filósofo italiano o paradigma imunitário, como emblema da modernidade, opera tanto no regime da soberania, com a presença dos direitos, quanto na lógica biopolítca. No limiar extremo do nazismo aparece de modo mais claro a pertinência entre os pontos que pareciam antinômicos, revelando "uma singular forma de indistinção que faz de um ao mesmo tempo o reverso e o complemento do outro” (ESPOSITO, 2010, p. 159).

Nessa percepção tornada possível pelo extremo do nazismo acerca da sobreposição da lógica soberana e biopolítica, da vida e da morte, costuradas pela prática imunitária, percebe-se uma separação biológica entre os que devem viver e aqueles que devem morrer. A terapêutica médica presente no nazismo é a indicação de um cuidado da vida de alguns que exige a morte de outros exige a imunização de alguns a respeito de outros. E tal elaboração revela que "o genocídio foi o resultado não da ausência, mas sim da presença de uma ética médica pervertida no seu contrário” (ESPOSITO, 2010, p. 166). A saúde do povo alemão, ou seja, a sua imunização ante o risco da doença judaica, precisou requerer o extermínio do inimigo. Somente a categoria imunitária “põe claramente a nu o nó mortífero que junta a proteção da vida à sua potencial negação” (ESPOSITO, 2010, p. 159).

Ainda que se desvie dos movimentos hiperbólicos do nazismo, esse nó mortífero não desaparece - foi ali apenas elevado ao seu ápice e evidência plena - uma vez que tal nó alimenta o próprio paradigma imunitário da modernidade. Sobre isso Esposito diz que:

Da guerra do e contra o terrorismo às migrações em massa, das políticas de saúde às demográficas, das medidas de segurança preventiva à extensão ilimitada das legislações de emergência, não há fenômeno de relevo internacional que seja estranho à dupla tendência que situa as histórias a que se faz referência numa única linha de significado: por um lado, uma crescente sobreposição entre o âmbito da política, ou do direito, e o da vida, por outro, uma implicação igualmente estreita, que parece derivar daquela, em relação à morte (ESPOSITO, 2010, p. 22).

O problema da degeneração, por exemplo, questão íntima à biopolítica, também evidencia o incômodo e o perigo que representam certas formas de vida ou certas condições biológicas perante as formas de vida consideradas saudáveis. Toda uma gama de diferentes discursos, desde os mais claros e assumidos a outros suavizados, pronuncia e fabrica o medo do contágio da degenerescência 
que certos comportamentos ou modos de vida parecem carregar. Drogados, viciados, vadios, imorais e desviados constituem perigos que justificam a defesa da sociedade em face de sua presença. Tornase preciso delimitar comportamentos ou traços degenerados, dar-lhes uma causa biológica, étnica ou social/cultural inquebrantável, para poder segregar e higienizar. É preciso imunizar a sociedade da presença problemática desses grupos e nesse movimento excluí-los da imunização. Fazer dessas formas de vida, vidas precárias, que não são originariamente precárias, mas que são assim posicionadas nas relações - na exposição do munus, alguns precisam ser protegidos e isso leva à fragilização de outros. À imunização, que é salvaguarda da vida, é inerente e também sua contrapartida o enviar para a morte. Imunizar alguns em face dos outros é sempre imunizar alguns e não outros - esse é o próprio movimento imunitário em seu ciclo de defesa e ataque da vida.

Assim, pensar a exposição para a morte exige, nesse quadro de referências, expor os movimentos que ordenam em diferentes posições as vidas. Pensar a produção da morte, nesse contexto, retira o olhar do agente ou do ato isolados que pensam em termos de (i)legitimidade, para requerer a análise das distribuições hierárquicas das vidas e os mecanismos de poder que se articulam e contribuem nas suas disposições. Discursos médicos, político-partidários, de movimentos sociais, políticas públicas, produção de pânicos morais, todos esses diferentes lugares passam a contar para uma efetiva compreensão dos processos imunitários.

É nesse sentido que Esposito afirma, de maneira categórica, o fato de que nunca, como atualmente, “os conflitos, as feridas, os medos que o dilaceram [o mundo] parecem pôr em causa nada menos do que a sua própria vida”, movimento que opera uma inversão no clássico motivo filosófico sobre o “mundo da vida” para considerar, a partir de então, a “vida do mundo” (ESPOSITO, 2010, p. 26). Essa modificação da bíos, levada a cabo por uma política tomada enquanto técnica e a sua leitura imunitária, requer seu entendimento não por uma perspectiva de mera reação, uma força reativa, aos processos desagregadores próprios da comunidade, mas como ação calculada da geração e controle do conflito, porém cujo cálculo pode lhe exacerbar e se reverter em autoimunização.

Tal como o corpo atua em relação ao antígeno, o sistema imunitário de uma comunidade parece operar de maneira similar (ESPOSITO, 2002, p. 59). Em um primeiro momento assimila aqueles que não se encaixam aos padrões de equilíbrio estabelecidos ao bom funcionamento do organismo social, forçando-os a se adequar aos seus modos de operação regular e saudável, mas para isso obriga a se revelarem constantemente, a fim de que sejam reconhecidos. Essa revelação permanente da subjetividade, para posterior assimilação e constrangimento à regra, é uma das técnicas dos procedimentos imunitários (NALI, 2013, p. 98-99).

A gestação e a proteção política da vida, pelos seus próprios meios, requer e aciona 
procedimentos de imunização consistentes na promoção de um equilíbrio vital da comunidade, mas que apenas se realiza na medida em que equaciona em seus cálculos a eliminação, via ataques imunitários, de elementos e fatores - indivíduos - compreendidos como risco de desagregação da própria comunidade ${ }^{14}$.

Nesses jogos procedimentais de demarcação de alvos de imunização, o cálculo operado no modelo de proteção negativa da vida leva em consideração um agregado de vidas a ser salvo em razão de suas qualidades verificadas in locu e em virtude de sua própria "humanidade”, critério este utilizado também para se determinar aqueles que serão expostos à morte, uma vez que representam um perigo à própria comunidade tomada enquanto corpo biológico. A ideia de humanidade subjacente a todos esses processos de imunização e compreendida como fator de diferenciação dos humanos dispostos numa hierarquia superior em relação a todas as outras espécies viventes, paradoxalmente, aderiu à própria matéria biológica, agora carregada de valores políticos. Nesse contexto, afirma Esposito, “confundida com a sua pura substância vital, e assim subtraída a qualquer forma jurídicopolítica, a humanidade do homem fica necessariamente exposta àquilo que pode simultaneamente salvá-la e aniquilá-la” (ESPOSITO, 2010, p. 19).

A leitura pelo viés da imunização nos coloca diante das produções de morte que ocorrem à revelia da permissão jurídica, na medida em que representam a proteção do próprio organismo social. Essa proteção do social depende da expulsão da igualdade generalizada. É só imunizando e, portanto, diferenciando e acobertando uns em detrimento de outros, que a vida cabe na política moderna. A moderna política da vida, assim, movimenta-se aplicando e desaplicando proteções imunitárias. É, deste modo, num contexto mais abrangente que a produção da morte deve ser pensada. Não se trata de balizar sua permissão ou negação legal, mas de analisar como a própria tessitura política moderna opera de modo antinômico, abrindo fendas na suposta igualdade e valor da vida em abstrato.

\section{CONCLUSÃO}

No cenário contemporâneo, não obstante o estruturado lugar do valor da vida e da pessoa humana firmemente construídos pela modernidade jusfilosófica, assistimos à crescente escalada de fronteiras divisórias entre tipos de vida. Por motivos religiosos, ou de pertencimentos políticos, ou médico-biológicos, ou morais, ou sanitários, etc., são fabricadas diferentes identidades marcadas por maior ou menor pertinência protetiva. Em resumo, ainda que tal cenário não seja palatável, vidas são

\footnotetext{
${ }^{14}$ De acordo com Esposito (2002, p. 69): “Ciò che ne risulta è un movimento bilanciato di neutralizzazione - chiaramente riconducibile alla logica immunitaria”.
} 
distribuídas com diferentes graus de valor, o que gera, para alguns grupos, um maior risco e uma exposição à morte. As operações de contenção do perigo provocado à sociedade pelos usuários de drogas problemáticos da chamada Cracolândia, em São Paulo, podem servir como exemplo desse contexto que foi aqui trabalhado. Para salvaguardar a vida, a própria vida - de quem vale menos - é lançada à morte.

A intenção foi a de delinear esse cenário e propor que, para compreendê-lo em termos mais efetivos, seria necessário ingressar no terreno das reflexões biopolíticas e pensar a exposição à morte de modo diverso de como a morte é usualmente pensada em termos jurídicos. As categorias jurídicas, políticas e filosóficas modernas, centradas no sujeito e em seus direitos de igualdade e valor humano seriam nesse contexto ineficazes - já que é a vida biológica e não a do sujeito de direito o objeto da biopolítica. Mas, mais que isso, a própria consideração da morte, situada em termos restritos de legalidade ou ilegalidade, também é insuficiente para dar conta da exposição à morte.

O plano da (i)legalidade, voltado para a permissão ou proibição do ato localizado, não considera o movimento tanatopolítico inscrito na própria elaboração da modernidade biopolítica. O que se pretendeu expor foi justamente o que os autores aqui trabalhados perceberam em relação à biopolítica moderna: sua condição de circuito de proteção e negação da vida, de relação entre bíos e poder em duas modalidades, uma asseguradora e outra letal - e ambas as modalidades operam juntas e de modo dependente. Nesse sentido, foi preciso elaborar uma proposta de pensar a exposição à morte para além dos institutos da pena de morte e do crime.

Ao sairmos do terreno tradicional da filosofia jurídico-política fortemente marcada por tais debates e adentrarmos ao ambiente aberto por Michel Foucault, tal tema ganhou novos e diferentes contornos.

Nesse cenário, não se buscou fundamentar a (i)legitimidade de um poder capaz de determinar a aplicação de pena capital por meio de uma sentença ou punir crimes. Tratou-se, antes, de investigar as relações de força que ocorrem de modo efetivo e que deflagram "mortes” diversas e contínuas, a despeito mesmo de sua proibição, em um contexto cuja tônica é o fazer viver. Buscou-se trazer para o debate a leitura que pretende rachar a fisionomia estática de uma modernidade subjetivista e humanista para mostrar que dentro da aparente lógica da defesa e proteção da vida, outros elementos se fazem presentes e remodelam aquela fisionomia posta.

Com Foucault e Esposito aparece o léxico biopolítico que exige outras visões e respostas de uma modernidade que já não é capaz de explicar, pela via de suas categoriais usuais, suas próprias contradições. Tais autores sugerem uma incursão nos conceitos políticos modernos para buscar seus legados escondidos, que, por sua vez, exigem novos conceitos. Um desses legados trata precisamente 
do problema de uma política de valorização e preservação da vida que admite e possibilita o seu reverso.

O nazismo, como momento paroxístico em que a biopolítica se transmutou no seu revés, serve de modelo para o ingresso na reflexão tanatopolítica; entretanto, os dois autores também apontam, cada um a seu modo, para os efeitos tanatopolíticos existentes, inclusive, após a queda dos governos totalitários, no seio das sociedades democráticas.

Seja por meio do acionamento do racismo de Estado para proteção da espécie, seja na compreensão da biopolítica como mecanismo de proteção negativa da vida, a produção da morte aqui considerada prescinde de determinação judicial. São essas mortes não ritualizadas judicialmente, mas que integram os cálculos do poder, o que aqui se tratou. Em outros termos, foi realizada uma reflexão da produção da morte amparada não no exame pontual da legalidade ou ilegalidade do ato que a realiza, mas do contexto biopolítico que carrega em si sua modalidade letal. Foi com um olhar atento à cisão dos modos de vida pertinentes e não pertinentes, relacionado ao modelo de poder no qual a proteção da vida requer a exposição de outras vidas, que a morte e suas condições foram aqui pensadas.

É pelo olhar da biopolítica fornecido por Foucault e Esposito, ou seja, do poder que se orienta e tem como objeto o simples fato da vida, seja majorando ou vulnerando suas condições, que alcançamos condições de pensar o cenário da produção da morte com novas categorias que não pensem a morte como efeito colateral de uma má distribuição de justiça ou de carência de aplicação de direitos humanos. Perceber o funcionamento de mecanismos de poder voltados para a vida e que nesse movimento a organizam segundo critérios de valor e utilidade - entre vidas que merecem viver e vidas que não merecem viver, com isso podendo ser expostas ao risco e extermínio - parece um caminho fundamental no cenário político-jurídico contemporâneo.

O olhar que aqui construímos observa tais índices pelas lentes das práticas de poder que atuam sobre a vida e encontram na sua ocorrência biológica elementos que selecionam tipos de vidas que podem ser eliminadas. A morte, para muito além de um mecanismo jurídico ou um ato de violência injustificado, pode ser efeito de uma lógica de poder. É preciso atentar para essa lógica e perguntar, com os autores que se dedicam à biopolítica, os sentidos possíveis à vida diante dos exercícios da política contemporânea.

Com a entrada em cena dos efeitos normalizadores do biopoder verificamos uma série de classificações hierárquicas, de vidas que valem mais que outras, de modo que tal análise mostra-se patente em um contexto no qual, apesar da garantia de proteção de direitos humanos, mortes (ou situações de exposição à morte) ainda ocorrem de acordo com critérios de estandardização. 
Tal constatação não implica, por óbvio, afirmar que o Estado atua diretamente na promoção dessas situações de morte. A análise deve ser feita dando um passo para trás: o biopoder se espalha pelo tecido social promovendo uma rede de diferenciações, podendo, eventualmente, ter no Estado um vetor de sua utilização. Não é o Estado que manuseia o biopoder, mas este que o atravessa e o faz atuar segundo seus desígnios normalizadores.

Desse modo, o trabalho de diagnóstico fornecido pelas lentes de tais autores nos concede uma atenção dúplice: em primeiro lugar, permite-nos verificar quais são as práticas e as técnicas que atuam no corpo social instaurando diferenciações entre as formas de vida - em relação às quais se poderão acionar mecanismos de proteção dos direitos humanos previstos no sistema jurídico. Em segundo lugar, possibilita vislumbrar quando o próprio direito ou o Estado são colonizados pela biopolítica e promovem tais valorações sociais, ainda que sejam concebidos como entes de proteção ou resguardo de direitos humanos. Estar atento a tais enigmas da biopolítica, para pensar a produção de morte inscrita nos próprios horizontes da racionalidade política moderna, é o que se busca, minimamente, com esta análise.

\section{REFERÊNCIAS}

BUTLER, Judith. Quadros de guerra: quando a vida é passível de luto? Tradução Sérgio Tadeu de Niemeyer Lamarão e Arnaldo Marques da Cunha. Rio de Janeiro: Civilização Brasileira, 2015.

CAMPBELL, Timothy. Política, Imunidade, Vida: O pensamento de Roberto Esposito no debate contemporâneo. In: ESPOSITO, Roberto. Termos da Política: comunidade, imunidade, biopolítica. Tradução Angela C. Machado Fonseca, João Paulo Arrosi, Luiz Ernani Fritoli e Ricardo Marcelo Fonseca. Curitiba: Ed. UFPR, 2017.

CORTE INTERAMERICANA DE DIREITOS HUMANOS (CORTE IDH). Caso Favela Nova Brasília Vs. Brasil. Sentença de 16 de fevereiro de 2017. Série C No 333. Disponível em: $<$ https://goo.gl/DPAqJP>. Acesso em: 16 set. 2017.

ESPOSITO, Roberto. Bios: Biopolítica E Filosofia. Tradução M. Freitas da Costa. Lisboa: Edições 70, 2010.

ESPOSITO, Roberto. Communitas: Origine e destino della comunità. Torino: Einaudi, 2006.

ESPOSITO, Roberto. Immunitas: Protezione e negazione della vita. Torino: Einaudi, 2002.

ESPOSITO, Roberto. Termos da Política: comunidade, imunidade, biopolítica. Tradução Angela C. Machado Fonseca, João Paulo Arrosi, Luiz Ernani Fritoli e Ricardo Marcelo Fonseca. Curitiba: Ed. UFPR, 2017. 
FONSECA, Angela Couto Machado. Biopolítica e Direito: fabricação e ordenação do corpo moderno. Belo Horizonte: Arraes Editores, 2016.

FONSECA, Ricardo Marcelo. Modernidade e contrato de trabalho: do sujeito de direito à sujeição jurídica. São Paulo: LTr, 2002.

FONSECA, Ricardo Marcelo. O poder entre o direito e a 'norma': Foucault e Deleuze na Teoria do Estado. In: FONSECA, Ricardo Marcelo (Org.). Repensando a teoria do Estado. Belo Horizonte: Fórum, 2004, p. 259-281.

FOUCAULT, Michel. Em defesa da sociedade. Curso no Collège de France (1975-1976). Tradução Maria Emantina Galvão. 2. ed. São Paulo: Editora WMF Martins Fontes, 2010.

FOUCAULT, Michel. História da sexualidade 1: A vontade de saber. Tradução Maria Thereza da Costa Albuquerque e J. A. Guilhon Albuquerque. Rio de Janeiro: Edições Graal, 2011a.

FOUCAULT, Michel. Vigiar e Punir: nascimento da prisão. Tradução Raquel Ramalhete. 39. ed. Petrópolis: Vozes, 2011b.

GRUPO GAY DA BAHIA. Quem a homotransfobia matou hoje? Disponível em: <https://goo.gl/Hq5qZO>. Acesso em: 16 set. 2017.

INSTITUTO DE PESQUISA ECONÔMICA APLICADA (IPEA) / FÓRUM BRASILEIRO DE SEGURANÇA PÚBLICA (FBSP). Mapa da Violência 2017. Disponível em: $<$ https://goo.gl/hVBdaf>. Acesso em: 16 set. 2017.

NALI, Marcos. A abordagem imunitária de Roberto Esposito: biopolítica e medicalização. Revista INTERthesis. Florianópolis, v. 9, n. 2, p. 39-50, 2012.

NALI, Marcos. Communitas/Immunitas: a releitura de Roberto Esposito da biopolítica. Revista Filosofia Aurora. Curitiba, v. 25, n. 37, p. 79-105, 2013.

TRANS RESPECT VERSUS TRANSPHOBIA WORLDWIDE (TVT). Trans Murder Monitoring Update. Disponível em: <https://goo.gl/FkLPJq>. Acesso em: 16 set. 2017.

Angela Couto Machado Fonseca Professora de Metodologia e Filosofia do Direito na UFPR (Departamento de Direito Privado). Bacharel em Direito, Bacharel em Filosofia, Mestre em Filosofia Moderna e Contemporânea (UFPR) e Doutora em Filosofia do Direito (UFPR). E-mail: fonseca_angela@yahoo.com.br

Dhyego Câmara de Araújo Bacharel em Direito pela Universidade Estadual de Londrina, Mestre em Direito do Estado e Doutorando em Direito do Estado pelo programa de Pós-Graduação da Faculdade de Direito da Universidade Federal do Paraná. Pesquisador dos núcleos Direitos Humanos e Vulnerabilidades e História, Direito e Subjetividade, ambos da UFPR. E-mail: dhyegohirota@hotmail.com 